\title{
BENDING AND SHEAR TESTS ON LAKE ICE
}

\author{
James T. Wilson and John M. Horeth
}

\begin{abstract}
This paper reports the results of bending and shear tests made on ice from Lake Michigan and on artificial ice so frozen as to have the same crystal orientation. The bend specimens normally failed in tension with an indicated tensile strength of about 200 psi. A marked increase of tensile strength with decreasing temperature was indicated. The shear strength was found to be about $100 \mathrm{psi}$. No temperature coefficient for shear strength could be detected. Specimens of the ice were studied in polarized light. It was observed that the optic axes of the ice crystals were usually normal to the surface of refrigeration. The crystal diameters were usually less than one inch.
\end{abstract}

Introduction--Even though a great deal of work has been done on the physical properties of 1ce and the literature is filled with references [BARNES, 1926; and DORSEY, 1940], relatively little information has been accumulated on the strength of lake ice. Work by BROWN [1926] on the bending strength and by FINLAYSON [1927] on the shearing strength of river ice furnished the only comprehensive data found in a rather intensive search of the literature. A summary by WEINBERG [1938] presents some useful data but it was impossible to examine the original references for most of the information.

The work described here was financed by the United States Coast Gard through Contract N6-232, Task order VI of the Office of Naval Research, and the tests were guided by their interest in ice-breaking.

Method--Tests were performed on specimens of artificial ice so frozen as to have the same crystal orientation as natural lake ice and also on specimens of lake ice picked up from the United States Coast Guard Cutter Mackinaw in northern Lake Michigan. All of the specimens were sawed out with ordinary wood saws having six to ten teeth per inch. None of the surfaces was polished and where possible the upper and lower surfaces of the ice sheet were left as surfaces of the test specimens. Most of the beams used for the bending tests were from $21 / 2$ to six inches in height, $21 / 2$ to five inches in width, and from 15 to 30 inches in length. Some of the specimens of lake ice were of larger cross section. The specimens tested in shear were usually approximately $21 / 2$ inches square and six inches long.

The blocks of artificial ice from which specimens were cut were frozen in wooden trays padded on the inside with excelsior or sponge rubber so that the expanston on freezing would not distort the block of ice. The padding was separated from the water by an inner membrane of thin sheet rubber. The trays were large enough so that several specimens could be cut from each block. Samples of the artificial ice were examined in polarized light and their crystal structure found to be very similar to that of the natural lake ice.

In both the bending and the shear tests the specimens were broken in a testing machine built for these experiments. Two four-inch I-beams approximately three $\mathrm{ft}$ in length were held parallel and one above the other by adjustable tie rods. A hydraulic jack fitted with a gage to read the oil pressure on the ram was attached to the bottom I-beam. For the bending tests two adjustable wooden bearing blocks were fitted to the lower surface of the upper I-beam and two more to a cross head on the ram of the jack. The extremities of the beam rested against the upper bearing blocks and the jack forced the two lower supports upward. This subjected the beam to pure bending. The supports were so positioned that the beams failed in tension in the span between the lower blocks. All of the beams tested were arranged with the surface of refrigeration horizontal, that is, with the optic axes of the crystals in the direction of the applied forces.

For the shearing tests a special shearing tool was constructed to be used in the press described above. The upper surface of the specimen rested against two rectangular wooden blocks faced with brass plates and separated by approximately three inches. The lower surface of the specimen was forced upward by a rectangular brass-faced wooden block fitted to the ram of the jack. This block was of a size and so positioned that it would just pass between the upper blocks. The specimens were all arranged as for the bending tests with the optic axes vertical. 
For both bending and shearing tests the applied force was read from the hydraulic gage on the jack. The jack and gage system were callbrated against an accurate test machine.

It was realized that the rate of loading might influence the results, although the work by BROWN [1926] had not indicated this to be the case for bending. It was impossible to make the rate of loading uniform but an attempt was made to carry each test to rupture in a time of one to three minutes. Bending tests made over much longer intervals $(50 \mathrm{~min})$ indicated that the rate of loading was not a critical factor.

The experiments on artificial ice were carried out in a refrigerated room in which the temperature remained constant to within a few degrees. Because of other experiments that were in progress in the room it was undesirable to raise the temperature to $32^{\circ} \mathrm{F}$. To obtain data at this temperature the specimens were removed from the refrigerator and allowed to warm up and then taken back in and broken within a very few minutes. Temperature measurements indicated that this Introduced no significant error.

The tests on lake ice were carried out on the United States Coast Guard Cutter Mackinaw during the latter part of January 1948. Specimens were obtained over the side and prepared and broken on deck.

The main sources of error are thought to reside in the measurement of the applied force and in the measurements of the specimen dimensions. These errors could easily amount to five per cent. However, the strengths of individual specimens varied so much from the average that it was not thought necessary to try to increase the accuracy of the measurements.

Results of strength tests--The results of the bending tests are presented in Table 1 and Figure 1. The data obtained by Brown in tests on ice from the St. Lawrence River are included. Each point in Figure 1 represents a single specimen.

Table 1--Results of bending tests

\begin{tabular}{|c|c|c|c|c|c|}
\hline Investigator & Ice & Temperature & $\begin{array}{l}\text { Number of } \\
\text { specimens }\end{array}$ & $\begin{array}{l}\text { Average } \\
\text { strength }\end{array}$ & Range \\
\hline \multirow{6}{*}{$\begin{array}{l}\text { Wilson and } \\
\text { Horeth } \\
\text { Brown } \\
\text { Wilson and } \\
\text { Horeth } \\
\text { Brown } \\
\text { Wilson and } \\
\text { Horeth }\end{array}$} & \multicolumn{3}{|c|}{8} & psi & psi \\
\hline & Artificial & 32 & 11 & 180 & $126-266$ \\
\hline & St. Lawrence & $28-30$ & 12 & 184 & $126-306$ \\
\hline & Lake Michigan & $12-20$ & 6 & 214 & $151-270$ \\
\hline & St. Lawrence & $14-16$ & 12 & 214 & $177-311$ \\
\hline & Artificial & -9 & 9 & 256 & $226-296$ \\
\hline
\end{tabular}

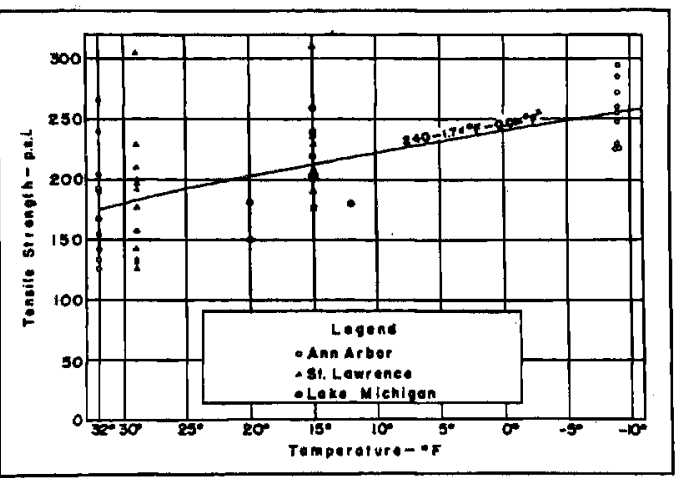

Fig. 1--Relation between tensile strength of ice and its temperature

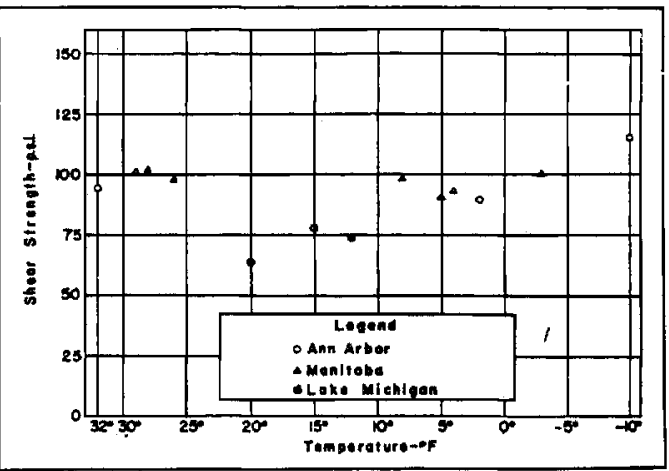

Fig. 2--Relation between shear strength of ice and its temperature 
The data indicates a relation between the tensile strength and the temperature of the form: Tensile strength $=240-1.7 \times{ }^{\circ} \mathrm{F}-0.01 \times\left({ }^{\circ} \mathrm{F}\right)^{2}$. The accuracy to which the coefficients are determined is very low.

The specimens of lake ice were typical of the full thickness of the ice sheet. In some cases a beam including the full thickness was broken and in other cases the thickness was divided into two beams. The lake ice usually had a cloudy zone up to two inches thick in the upper portion. The total thickness was about one foot. The cloudy zone did not seem to cause appreciable weakening of the beams.

The results of the shear tests are presented in Table 2 and Figure 2. The data obtained by FINLAYSON [1927] for river ice are included.

Table 2--Results of shearing tests

\begin{tabular}{|c|c|c|c|c|c|}
\hline Investigator & Ice & Temperature & $\begin{array}{l}\text { Number of } \\
\text { specimens }\end{array}$ & $\begin{array}{l}\text { Average } \\
\text { strength }\end{array}$ & Range \\
\hline & \multicolumn{3}{|c|}{${ }^{\bullet} F$} & psi & psi \\
\hline Wilson and Horeth & Artificial & 32 & 10 & 94 & $41-161$ \\
\hline Finlayson & River & 29 & . & 101 & $\cdots \cdot$ \\
\hline Finlayson & River & 28 & . & 102 & $\ldots$ \\
\hline Finlayson & River & 26 & . & 98 & $\ldots$ \\
\hline WiIson and Horeth & Lake Michigan & $12-20$ & 13 & 75 & $39-103$ \\
\hline Finlayson & River & 8 & . & 99 & $\ldots$ \\
\hline Finlayson & River & 5 & . & 91 & $\ldots$ \\
\hline Finlayson & River & 4 & . & 94 & $\ldots \ldots$ \\
\hline Wilson and Horeth & Artificial & 2 & 10 & 90 & $58-120$ \\
\hline Finlayson & River & -3 & . & 101 & $\ldots$ \\
\hline Wilson and Horeth & Artificial & -10 & 10 & 115 & $70-173$ \\
\hline
\end{tabular}

The points plotted in Figure 2 are averages. Finlayson gives only averages and states, "Each coordinate point represents the average of many tests." He does not give the range for each temperature but does state that the maximum value found was 353 psi which indicates a range somewhat greater than ours.

It will be noted that the average for lake ice is lower than for the artificial or river ice. The 13 specimens of lake ice represent four different vertical sections through the ice sheet. For three of the sections a specimen was cut from the top, middle, and bottom of the sheet. For the fourth section an extra middle specimen was cut. If the upper specimens which usually included cloudy ice are not included the average becomes 84 psi.

Finlayson remarks that artificial ice is only about 80 per cent as strong as natural ice. However, he does not state how his artificial ice was frozen.

Crystal size and orientation--It is well known that ice crystallizes in the hexagonal system and that in natural lake and river ice the crystals are usually arranged with the optic axes vertical [DORSEY, 1940]. However, a careful search of the literature furnished almost no information as to the size of the crystals. It was considered desirable to keep the cross section of all the test specimens several times larger than the crystal diameters. For this reason the crystal size and orlentation were studied.

Sections of both the lake ice and the artificial ice were examined in polarized light. Sections about four inches square and $1 / 4$ to $1 / 2$ inches thick were cut parallel to the surface of refrigeration and examined by placing them between ten-inch discs of polaroid. The vibration directions of the polaroid discs were crossed at right angles and the system illuminated from behind. In this manner the crystal diameters and the approximate orientation of the optic axes could be determined easily.

Figures 3 and 4 are photographs of two sections of lake ice cut from a vertical prism extending from the top to the bottom of a 12-inch thick ice sheet. Figure 3 shows a section from near the top but below the cloudy ice and Figure 4 shows a section about two inches up from the bottom. A number of such prisms were sectioned and in every case the crystals were larger in the bottom of the sheet. Very few sections examined showed crystals more than one inch in diameter. 


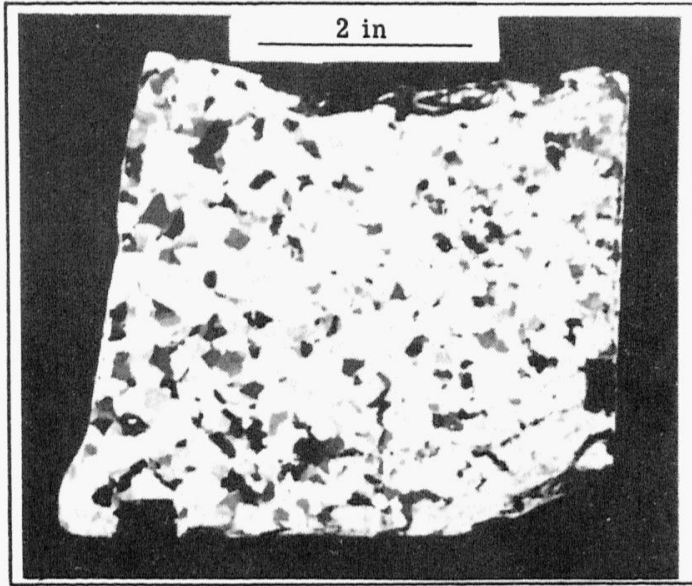

Fig. 3--Photograph of a plate of lake ice between crossedpolaroids; section cut parallel to surface just underneath the cloudy top part of the ice

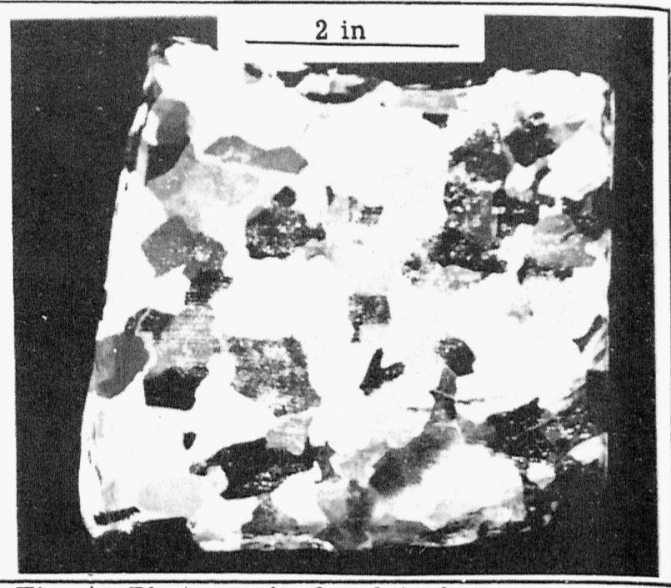

Fig. 4--Photograph of a plate from same prism as 3 , but about two inches from and parallel to the bottom surface of the ice

The crystal diameters in the artificial ice were usually about $1 / 2$ inch. The diameter was usually quite uniform from bottom to top. It is thought that there was. nothing so different in the size or orientation of the crystals in the lake and artificial ice as to cause any significant difference in their strengths.

\section{References}

BARNES, HOWARD T., Ice engineering, First Ed., Reneuf Pub. Co., Montreal, 1928.

BROWN, E., Report of the Joint Board of Engineers on St. Lawrence Waterway Project, pp. 423$453,1926$.

DORSEY, N. ERNEST, Properties of ordinary water substance, First Ed., Reihold Pub. Corp., New York, 1940.

FINLAYSON, JOHN N., Tests on the shearing strength of ice, Canadian Eng., v. 53, no. 1, pp. $101-103,1927$.

WEINBERG, BORIS, Mechanical properties of ice, Bull. No. 23, International Union of Geodesy and Geophysics, Riga, 1938.

Department of Geology and Institute of Engineering Research, University of Michigan, Ann Arbor, Michigan

(Manuscript received June 18, 1948; presented at the Twenty-Ninth Annual Meeting, Washington, D. C., April 22, 1948; open for formal discussion until May 1, 1949.) 